Revista de Filosofía

ISSN: 0034-8244

https://dx.doi.org/10.5209/resf.62163

\title{
Democracia y justicia procedimental
}

\author{
Diego Alejandro Otero Angelini ${ }^{1}$
}

Recibido: 31 de octubre de 2018 / Aceptado: 7 de abril de 2019

Resumen. En este artículo analizo el concepto de la democracia como un sistema de justicia procedimental en contraste con la democracia como mecanismo de toma de decisión y ejercicio del poder político de Schumpeter. La idea de la democracia como un sistema de justicia procedimental que expongo está vinculada al pensamiento de John Rawls. Al final del artículo muestro cómo esta conceptualización, en el contexto de las sociedades plurales, garantiza en mejor medida las libertades y la igualdad generando condiciones de estabilidad institucional.

Palabras clave: Democracia; justicia procedimental; liberalismo; igualitarismo.

\section{[en] Democracy and procedural justice}

Abstract. In this paper I analyze the concept of democracy as a system of procedural justice in contrast to democracy as a mechanism of decision making and power exercise developed by Schumpeter. The idea of democracy as a system of procedural justice that I bring forward is linked to John Rawls's thought. At the end of this paper I show how this concept, in the context of social pluralism, outperforms other options in the guarantee of liberty and equality generating conditions of institutional stability.

Key words: Democracy; procedural justice; liberalism; equality.

Sumario: 1. Formatividad; 1.1. La forma formante como guía del proceso formativo; 1.2. La ejemplaridad de la obra; 1.3. "Imitación" pareysoniana, "repetición" heideggeriana; 2. Interpretación; 2.1. Metafísica de la forma e incremento del ser; 3. Conclusiones; 4. Referencias bibliográficas.

Cómo citar: Otero Angelini, D. A. (2020): "Democracia y justicia procedimental", en Revista de Filosofía 45 (1), 105-119.

1diego_otero1@hotmail.com 
A principios del siglo XX estaba presente un debate sobre la democracia que sigue teniendo profunda relevancia. Por un lado, ejemplificando arquetípicamente, aunque no necesariamente siendo el primero en hacerlo, tenemos la idea de la democracia deweiana. El concepto democrático de Dewey trasciende la comprensión de la democracia como sistema de gobierno y la estipula como la fibra fundamental de la estructura social: la democracia como cultura. Por otro lado, Joseph Schumpeter planteó la democracia como un método de decisión de actos políticos: "La democracia es un método político, esto quiere decir, un cierto tipo de arreglo institucional para alcanzar decisiones políticas -legislativas y administrativas-, por tanto incapaz de ser un fin en sí mismo, independientemente de las decisiones que produzca bajo ciertas condiciones históricas" (Schumpeter 2008, p. 242). Estas posturas representan dos extremos de la comprensión de la democracia dentro de los que, para poder calificar los actos públicos de buenos o justos, sería necesario una visión compartida de lo que el bien y la justicia significan. En el primer caso porque todos tienen fundamentalmente la misma cultura democrática y, en el segundo, porque sin una visión compartida es imposible realizar un juicio de ese tipo, pues la democracia es sólo un mecanismo de toma de decisión.

En este artículo mostraré cómo este debate puede ser superado si, en lugar de pensar la democracia sólo en términos de procedimiento o de cultura, conducimos el análisis a un punto más o menos intermedio: la democracia como un sistema de justicia procedimental. Un desarrollo de la democracia en esos términos supondría que la justicia es uno de los fines propios de la democracia, lo que contradiría la concepción schumpeteriana.

Para mostrar que dicho planteamiento es posible, primero expondré el que parecería, según Schumpeter, ser el mayor reto para poder definir un fin para la democracia que trascienda la mera toma de decisiones: el problema del pluralismo. Las democracias contemporáneas están condicionadas, dada la realidad histórica en la que nos encontramos, a existir bajo circunstancias de pluralismo; es decir, el tiempo de plantear una sociedad democrática en la que la mayoría de las personas compartan valores morales, religiosos, políticos $\mathrm{u}$ otros similares ha pasado, al menos en el contexto del Estado-nación moderno. Una vez que haya concluido la exposición del pluralismo y los retos que dicha situación implican, definiré lo que es un sistema de justicia procedimental recurriendo al análisis que desarrolla John Rawls en Teoría de la Justicia. Después trataré el concepto de democracia como un sistema de justicia procedimental influenciado por el pensamiento de Rawls, aunque igualmente nutrido por el análisis de pensadores como Arend Lijphart o Adam Przeworski, y el modo en que la democracia puede convertirse en medida misma de justicia para una sociedad democrática. Para concluir esbozaré algunas de las consecuencias económicas que dicho planteamiento podría tener. Si la democracia puede ser entendida como un sistema de justicia procedimental, eso significa que no todos los actos y decisiones políticos pueden ser razonablemente aceptados. Por lo mismo, no sería suficiente con ser elegidos a través del método democrático para ser aceptables bajo un esquema de justicia y, en consecuencia, las sociedades democráticas tenderán a tener ciertas instituciones similares en la medida en que algunas cumplan con las condiciones de la democracia misma de mejor manera.

De fondo, el punto que intentaré analizar es la posibilidad y las consecuencias de desarrollar comunidades políticas que tienen su punto de cohesión y criterio de justificación pública en su identidad democrática y no en función a alguna creencia 
particular que conduzca a una idea del bien compartida por todos. En palabras de Joshua Cohen:

Si la comunidad política depende de compartir una moral comprehensiva o una perspectiva religiosa, o una identidad nacional definida en términos de dicha perspectiva, entonces el pluralismo razonable elimina la posibilidad de la comunidad política. Pero una concepción alternativa de la comunidad política conecta la perspectiva deliberativa con el valor de la comunidad. En particular, al requerir la justificación - de las políticas públicas - en términos aceptables para todos, la democracia deliberativa provee un tipo de autonomía política: que todos los que son gobernados por decisiones colectivas -que esperan ser gobernar su propia conducta por esas decisiones- debe encontrar las bases para esas decisiones aceptables. En esta seguridad de autonomía política, la democracia deliberativa alcanza un importante elemento del ideal comunitario. (Cohen 2009, p. 163)

\section{El problema del pluralismo en las sociedades democráticas y la justicia procedimental}

Mucho ha sido dicho ya sobre el problema del pluralismo en las sociedades democráticas contemporáneas. En general se asume, correctamente me parece, que dadas las condiciones de pluralismo es imposible ofrecer un concepto del bien común bajo el cual pueda operar una sociedad democrática de modo adecuado. Si el pluralismo es una condición que imposibilita la adopción justificada de un fin político aceptable para todos, como es el concepto del bien común, entonces el pluralismo aparentemente implica que, al menos en el caso de las sociedades democráticas y en la gran mayoría de sus actos políticos, el ejercicio del poder sea una imposición de un grupo sobre otro.

La postura schumpeteriana de la democracia retoma el hecho que las democracias han atentado, en ocasiones, en contra las libertades de ciertos grupos políticos determinados. Cuando la democracia es entendida en este modo, asume Schumpeter, es posible comprender la realidad de la democracia como un sistema de opresión política. Es decir, a través del método democrático podemos elegir leyes y gobernantes que discriminen a ciertos grupos. Un ejemplo histórico claro es que los americanos democráticamente permitieron la existencia de las leyes "Jim Crow", que promovían la discriminación por motivos de raza.

Si reconocemos la validez del análisis de Schumpeter, por tanto, parecería que de una nación democrática no es posible prever qué forma tomarán sus leyes concretas en materia de libertades políticas, civiles o económicas. Este problema se explica, desde un punto de vista filosófico, porque, contrario a lo que la "doctrina clásica" o cultural de la democracia, el objetivo del proceso democrático no es alcanzar o procurar el bien común; Schumpeter es muy claro al respecto:

No existe, para empezar, una cosa así como un bien común determinado en el que todas las personas puedan estar de acuerdo o puedan ser obligadas a estar de acuerdo a través de la fuerza de un argumento racional. Esto no es principalmente por el hecho que algunas personas puedan desear otras cosas que el bien común, sino por el hecho mucho más fundamental que para los diversos individuos y grupos el bien común está destinado a 
significar cosas distintas. Este hecho, escondido para los utilitaristas por lo estrecho de su comprensión del mundo de las evaluaciones humanas, introduce desacuerdos sobre cuestiones de principio que no pueden ser reconciliadas por argumentos racionales debido a que los valores últimos - nuestra concepción de lo que la vida y la sociedad debe de serestá más allá del alcance de la mera lógica. (Schumpeter 2008, p. 252)

Este escepticismo por las posibilidades de determinar el bien común, y un concepto de justicia que nos sirva en el contexto de las sociedades democráticas actuales, permea la filosofía política contemporánea. Este es el problema que aborda Rawls con el desarrollo de la justicia como imparcialidad. Sin embargo, antes de cerrarnos a la posibilidad de desarrollar criterios normativos para juzgar los actos políticos en una democracia, vale la pena buscar responder la pregunta que plantea en El liberalismo político, su segunda gran obra: “(...) la pregunta fundamental sobre la justicia política en una sociedad democrática, ¿cuál es la más apropiada concepción de la justica para especificar los términos justos de cooperación social entre ciudadanos considerados libres e iguales y como miembros plenamente cooperadores de una sociedad durante una vida completa, de una generación al a siguiente?" (Rawls 2005, p. 3)

Si asumiéramos que la justicia depende de una idea del bien para poder ser adecuadamente considerada, ${ }^{2}$ y que la comprensión de la democracia de Schumpeter fuera correcta, la pregunta rawlsiana carecería de sentido. ¿Cómo es posible hacer una pregunta como esa para un método de decisión en el cual no hay posibilidades de argumentos racionales para las preguntas fundamentales de la justicia y el bien? Si la cuestión de la justicia es una en donde lo justo y lo bueno están profundamente relacionados, parece que para poder hacer una pregunta sobre la justicia en una sociedad democrática, tendríamos que asumir que nuestra democracia necesita "apellido": democracia liberal, democracia comunitarista, democracia confesional u otra. Es necesaria una idea del bien que oriente la toma de decisión para poder juzgar las acciones como justas o injustas, independientemente de si el método es democrático o autoritario.

Considero que desde el pensamiento de Rawls es posible demostrar que el concepto de democracia de Schumpeter es insuficiente al no plantear términos justos de interacción y, cuando conceptualizamos la democracia de un modo alternativo, es posible reconocer que ésta es efectivamente un método de elección pero, al mismo tiempo, es medida de justicia para los actos políticos, sus implicaciones económicas y una cierta concepción del bien político con sus propios valores. Con ese objetivo en mente, es importante tener en cuenta la idea rawlsiana de la sociedad como un "sistema justo de cooperación durante el tiempo, de una generación a la próxima" (Rawls 2005, p. 15). Es decir, aun cuando algunas personas o grupos consideren que la sociedad debería de ser más que un sistema de cooperación, parece que esta idea se encuentra de fondo en cualquier comprensión del Estado en su dimensión política: la sociedad como un lugar en donde los individuos pueden vivir sus vidas de modo que, a partir de compartir su existencia dentro de dicho contexto, tengan ciertas ventajas racionales frente a la posibilidad de vivir fuera de una sociedad; entendiendo que dichas ventajas provendrán de la convivencia con otros individuos bajo términos justos de cooperación.

Este sería el caso de la ética utilitarista y la ética de virtudes, por ejemplo. 
¿Cuáles son esos términos justos de cooperación? ¿Qué idea del bien se encuentra de fondo para poder determinarlos? La propuesta de Rawls es que no es necesaria una idea de bien determinada para poder definir dichos términos justos de cooperación; de ese modo sería compatible con la existencia del pluralismo de las sociedades contemporáneas. Para explicarlo es útil retomar el ejemplo que usa Rawls en Teoría de la Justicia al explicar los sistemas de justicia procedimentales (Rawls 1999, pp. 74-77). Supongamos que tenemos un pastel enfrente y lo queremos repartir entre varios individuos, ¿cuál debería de ser el criterio de repartición? Una condición que impone Rawls es que todos los presentes queremos la mayor cantidad de pastel posible porque, si no fuera así, sólo sería necesario preguntar quién tiene más hambre, lo que no parece ser una respuesta satisfactoria para la mayoría de los problemas de distribución en las sociedades actuales. Por el contrario, como la condición de Rawls presupone, las personas tienden a ser egoístas racionales que, en la medida de lo posible, buscarán la mayor cantidad de bienes posibles.

Para solucionar el problema podríamos ofrecer al menos un par posibilidades, en la medida en que asumamos que la imposición arbitraria de la fuerza no es aceptable:

1. Preguntarnos quién lo merece más, aunque no es claro qué criterio moral relevante sería útil.

2. Preguntarnos quién lo necesita más. Tampoco queda del todo claro cómo definimos necesidad y, aunque en algunos casos pudiéramos llegar a un acuerdo sobre un criterio de urgencia, no sucede así para todos los casos.

Las dos posibilidades dependen de que las partes tengan una idea de bien compartida, pues la idea del mérito y la necesidad no son condiciones evidentemente objetivas. Ya que podemos suponer que esa idea de bien compartida no existe, pues es la implicación fundamental del pluralismo como un hecho en la sociedad, las dos posibilidades fallan.

¿Cuál es la respuesta de Rawls? Para hacer una repartición justa, pongamos como regla que sea una sola persona quien haga el corte del pastel, pero que sea él el último en tomar su porción. En la medida en que todos deseen la mayor cantidad posible, el mejor resultado para el que corta el pastel es que todos coman lo mismo. La idea de la justicia procedimental es atractiva para solucionar este problema porque deshace la necesidad de juzgar los resultados de la repartición de acuerdo a alguna idea del bien determinada y nos permite, para juzgarlos, hacerlo sólo en la medida en que se atiendan las normas iniciales.

De lo dicho hasta este punto, parece que hay dos cosas que están supuestas en los sistemas de justicia procedimental: por un lado, el sistema de justicia procedimental debe ofrecer resultados que consideremos deseables en mayor proporción que alguna otra opción disponible, aunque saber qué consideramos deseable puede estar sujeto a discusión, y, por otro lado, al parecer las condiciones del procedimiento deben de ser aceptables a las partes que formarán parte del proceso, de lo contrario no podría ser candidato a ser juzgado como justo de inicio. Si los resultados no son aceptables en general, o al menos comparativamente frente a otras opciones, el sistema fracasa. Si las condiciones no son aceptables, tampoco puede ser considerado justo o aceptable aun cuando los resultados fueran aceptables.

¿Cómo relaciono el ejemplo al problema de la democracia? La cuestión puede ser abordada del siguiente modo: ¿Existen en las democracias contemporáneas ciertos 
términos fundamentales que nos permiten identificar cuándo un procedimiento es justo independientemente de su resultado? Si sí existen, ¿es posible prever cómo se configurarán ciertas instituciones e incluso ciertas leyes? Es decir, si las democracias contemporáneas, para funcionar en tanto democracias, exigen ciertos criterios procedimentales mínimos, únicamente los productos (actos políticos) del método democrático que respeten dichos criterios podrán ser considerados justos $\mathrm{y}$, al mismo tiempo, podemos suponer que la cantidad de actos que pueden ser considerados democráticos será limitada.

Esta postura, y en especial los actos políticos democráticos que se siguen de ella, está abierta a críticas que sostengan el bien y la justicia como virtudes vinculadas a una idea del bien concreta y no procedimental. Es decir, un sistema de justicia procedimental democrático no promete entregar resultados que siempre dejen satisfechas a todas las partes, pues no es perfecto y los resultados pueden ser juzgados más allá de los criterios del procedimiento mismo por parte de los integrantes de una democracia. Por ejemplo, cuando la Suprema Corte en una nación democrática tiene poderes de revisión judicial amplios, como es el caso de México o Estados Unidos, podemos razonablemente preguntarnos si sus decisiones son verdaderamente justas o buenas cuando llevan a cabo un acto legislativo. En la medida en que asumamos que el procedimiento democrático es la medida de justicia, podríamos afirmar que las decisiones de la Corte, cuando impliquen el desechar una ley aprobada por un legislativo democráticamente elegido, que lleva a cabo el proceso de modo correcto ateniéndose a las exigencias democráticas, son en injustas independientemente de qué sea lo que elijan. Igualmente, los casos de legislación judicial, a partir de la generación de jurisprudencia que adquiere el papel de ley y limita las acciones legislativas, serían injustos si no se mantienen en garantizar el correcto proceso democrático. Por el contrario, si sostenemos una idea de la justicia vinculada a una idea del bien, no fundamentada en el procedimiento democrático, podríamos afirmar que las decisiones judiciales que tienen este carácter legislativo pueden ser consideradas justas aun cuando no formen parte de un procedimiento democrático.

En cualquier caso Rawls, defensor de la idea de la justicia procedimental, no afirma que todas las acciones llevadas a cabo en una sociedad, no importa si está bien ordenada o no, serán perfectamente justas. De hecho asume que, por el grado de complejidad que supone una democracia contemporánea, la justicia procedimental debe de ser considerada intrínsecamente imperfecta.

\section{La democracia como sistema de justicia procedimental}

Definir la democracia en el contexto actual es un proyecto complicado. Un modo generalmente aceptable al referirse a la democracia como una forma constitucional afirma que es en la que el poder político es controlado y ejercido por los ciudadanos. Esta definición, sin lugar a dudas, es imprecisa.

Si la democracia solo puede ser definida en términos de una forma de gobierno en que el poder político es ejercido por los ciudadanos, entonces la democracia, en el contexto del Estado-nación moderno, es inexistente. De ordinario, en una sociedad que denominaríamos democrática no todos los ciudadanos ejercen el poder político, ya sea directa o representativamente, ni, de igual modo, todos los actos políticos son producto de un ejercicio democrático. Aun aceptando la universalidad del voto, lo 
que es un hecho histórico reciente en las sociedades democráticas, hay discriminación en la participación por razones de edad o si el ciudadano en cuestión es infractor de la ley (dependiendo el tipo de falta), por ejemplo. Por otro lado, incluso en los Estados con democracias avanzadas, ciertas decisiones son llevadas a cabo por funcionarios o servidores públicos no elegidos mediante vías democráticas; un par de ejemplos son, en la mayoría de las democracias, la función de las Cortes, en especial los tribunales supremos, y la operación de los Bancos Centrales independientes.

Dicho de otro modo, si tenemos alguna esperanza de encontrar en una comprensión de la democracia un criterio normativo aceptable de actos políticos, es necesario trabajar con un concepto más adecuado que la del ejercicio del poder político por parte de los ciudadanos sin más. Para esto la idea de la democracia como el autogobierno del pueblo puede servir como un primer paso. Como afirma Przeworski, si al referirnos al autogobierno del pueblo estamos intentando afirmar que todos los integrantes del pueblo están de acuerdo en las decisiones concretas, como si cada uno de los integrantes de la comunidad fueran igualmente los legisladores de cada acto, el ideal de autogobierno es fundamentalmente incoherente (Przeworski 2010, p. 17). Después de todo, como afirmé en la sección pasada, el hecho del pluralismo impide que podamos aceptar que todos los actos políticos que ocurren en democracia sean aceptables para todos en cada caso; además, no todos los ciudadanos participan en los procesos políticos por muy diversas y legítimas razones.

Asumiendo la dificultad de definir la democracia en esos términos, es mejor transitar a una caracterización de la democracia en su dimensión política en términos descriptivos:

Como un concepto empírico, la "democracia" se puede referir a cualquiera de al menos tres dimensiones que son relevantes para el modo en que el poder es organizado y ejercido: (a) el proceso deliberativo, es decir, el proceso mediante el que diversas opciones de acción son propuestas, discutidas y sus fortalezas y debilidades son evaluadas, (b) a los mecanismos de decisión mediante el cual un grupo elige un camino de acción, y (c) a la ejecución e implementación de esas decisiones. (Geuss 2001, p. 114)

La ventaja de utilizar este tipo de conceptualización de la democracia es que nos permite superar el peligro de asumir la existencia de una voluntad popular que se identifique con un ideal del bien común. Como afirma Raymond Geuss, haciendo más aguda la crítica de Schumpeter: "Con lo difícil que es decir lo que un individuo desea, transferir o extender esto a un grupo, en especial a un grupo mal definido como "el pueblo", agrega la dificultad" (Geuss 2001, p. 116). Asumir que la categoría de "el pueblo" existe, como si fuera una "entidad" separada de los miembros que lo integran y que, por lo mismo, puede ser designado un modelo de gobierno que satisfaga los bienes para dicho ser, es una continuación del uso de la analogía organicista aristotélica que, bajo la existencia del pluralismo, adopta tintes opresivos ante la preferencia de los ciudadanos.

Ahora bien, después de rechazar la idea de la democracia como un sistema de autogobierno de cada uno de los ciudadanos, por ser una idea inconsistente con la realidad política, y de la democracia como el autogobierno del "pueblo", al no existir dicha entidad llamada "pueblo" que posea intereses, objetivos y bienes particulares para sí, quisiera considerar la democracia en los sentidos que planteó Geuss: como proceso deliberativo, como mecanismos concretos de decisión o la ejecución de 
la decisiones. Esta descripción de la democracia, en particular en su dimensión deliberativa, es altamente compatible con la idea de la justicia procedimental rawlsiana que traté atrás:

Siendo más que una forma de política, la democracia, desde la perspectiva deliberativa,
es un marco de referencia de las condiciones sociales e institucionales que facilitan las
condiciones de discusión libre entre ciudadanos iguales -proveyendo las condiciones
favorables de participación, asociación y expresión-al tiempo que vincula la autorización
del ejercicio del poder público (y el ejercicio mismo) a dicha discusión-al establecer el
marco que asegura la respuesta y rendición de cuentas del poder político a ella mediante
elecciones competidas regulares, condiciones de publicidad, supervisión legislativa y
más. (Cohen 2009, p. 160)

La democracia deliberativa debería de funcionar como un proceso de selección de decisiones y actos políticos que, dependiendo de la manera en que integremos el proceso, podrá ser considerado justo o injusto en su mecanismo, aunque no siempre arroje resultados justos perfectos; recordemos que, al menos según la consideración de Rawls, no podría haber uno perfecto en cualquier caso. Si ciertas condiciones procedimentales se sostienen, incluso en los casos en que una persona no esté de acuerdo con las decisiones políticas a las que se llegue, tenderá a aceptarlas en la medida en que, siendo democráticas, no serán ilegítimamente forzadas y podrían ser revisadas en el futuro.

Dicho lo anterior queda analizar cuáles son algunas de las condiciones del proceso deliberativo democrático que le garantizan un cierto nivel de justicia en sentido procedimental. Es decir, un sistema de decisión colectivo en el que se reflejen del mejor modo posible las preferencias de los ciudadanos y que, al mismo tiempo, permita que libremente puedan elaborarlas, defenderlas y conducirlas por un proceso de escrutinio público de decisión. Adam Przeworski define cuatro condiciones fundamentalmente (Przeworski 2010, p. 32): (1) igualdad en la influencia que un ciudadano puede, si lo desea así, tener en el proceso, (2) todo participante debe tener un mecanismo de influencia efectivo, (3) las decisiones colectivas deben de ser efectivamente implementadas por aquellos que sean elegidos para hacerlo y (4) el sistema legal debe asegurar que la cooperación y convivencia suceda bajo condiciones de libertad.

De seguirse estas condiciones los actos políticos dentro de una sociedad determinada pueden ser analizados de acuerdo a su apego al proceso democrático y, en consecuencia, juzgarlos como justos o injustos. En la medida en que la democracia genera las condiciones de imparcialidad mejor justificadas si garantiza a todos las mismas posibilidades de influenciar el proceso, podremos afirmar que el proceso será considerado justo por las partes aunque no suceda así, necesariamente, con los actos que se deriven de él.

Dicho de otra manera, aun concediendo que la democracia, como lo suponía Schumpeter, es un sistema de ejercicio del poder político que no opera en la búsqueda del bien común, eso no implica que no pueda ser evaluado en su funcionamiento como justo o injusto. Lo que es más, si por el contrario insistiéramos que la idea de la justicia requiere de algún tipo de idea del bien, podría considerarse que es una idea 
política del bien ${ }^{3}$ que no supone un contenido de dicha idea que fuera incompatible con el pluralismo. Bajo dicha idea, el proceso puede ser categorizable como justo o injusto no por su capacidad de alcanzar un "bien común", sino por su adecuación a los requisitos o condiciones mismas del proceso democrático. Rawls asume este hecho en la medida en que la concepción de la justicia, la justicia como imparcialidad, supone la posibilidad de construir un sistema de justicia procedimental compatible con nuestros juicios considerados, en equilibrio reflexivo con ellos, que nos permite balancear dos exigencias democráticas fundamentales: la igualdad y la libertad.

Si los valores fundamentales en una democracia, para que pueda ser considerada como tal, son la libertad y la igualdad, un análisis sobre qué tan justa será podrá fundamentarse en la medida en que dichos valores estén presentes en el sistema. Esta idea está supuesta en las condiciones de Przeworski o en los criterios de Robert Dahl para la poliarquía (Dahl 1998, p. 37): participación efectiva, igualdad de voto, comprensión ilustrada, control sobre la agenda y la inclusión de todos los adultos. Estos criterios suponen los valores de la igualdad y la libertad para cada uno de los ciudadanos y, al mismo tiempo según Dahl, son condiciones para garantizar la libertad y la igualdad a largo plazo. Los valores sirven como fundamento y fin del proceso.

Si la democracia puede ser entendida como un sistema de acción política y como una medida fundamental de justicia que pueda ser aceptable para los ciudadanos que en ella viven, siempre y cuando acepten la libertad e igualdad de todas las personas, podríamos analizar las condiciones, instituciones y actos políticos concretos en términos de la democracia misma y, por lo tanto, de su aceptabilidad como mecanismo de justicia procedimental. De ser así, es posible afirmar que las democracias pueden ser comparadas entre sí en función de qué tan democráticas son sus instituciones.

La idea de usar la democracia misma como medida, en particular la búsqueda de la igualdad política como un objetivo democrático fundamental, está presente en Patterns of Democracy, donde Arend Lijphart lleva a cabo una comparación entre los dos modelos fundamentales de democracia en los Estados contemporáneos (mayoritaria y proporcional). Lijphart procura descifrar las distinciones institucionales entre ambos modelos así como evaluar su desempeño. Dos conclusiones de su trabajo adquieren especial relevancia en el contexto de este artículo. Por un lado, las democracias proporcionales tienden a ser más democráticas en la medida en que cumplen mejor con la garantía de igualdad política entre todos los ciudadanos pues, en los esquemas mayoritarios, aquellos que pertenecen a una minoría tienden a no ser representados en las instituciones con igualdad (Lijphart 2012, p. 7). Por otro lado, las democracias proporcionales, basadas en el consenso y que tienen instituciones políticas que satisfacen mejor los valores de democracia que relaciono con la justicia (libertad e igualdad) tienden a tener un desempeño similar, en algunas medidas incluso mejor, y cuentan con mucha mayor aceptación por parte de los ciudadanos:

\footnotetext{
En el Liberalismo Político Rawls analiza la idea del bien desde una perspectiva política en la quinta conferencia, "La prioridad de lo justo y las ideas del bien". En este análisis hace hincapié en que una sociedad liberal, ordenada por la justicia como imparcialidad no puede estar orientada a una idea del bien particular debido a la existencia del "hecho del pluralismo", de modo que pueda ser aceptable bajo un consenso traslapado. Dadas estas condiciones, la idea del "bien político" supone que la sociedad política bien ordenada es un bien para los ciudadanos, al menos en parte, porque "les asegura el bien de la justicia y de las bases sociales del mutuo autorespeto." (Rawls 2005, p. 203)
} 
La segunda conclusión importante tiene que ver con el desempeño político de los gobiernos democráticos: en lo que respecta al ejercicio ejecutivo, las democracias mayoritarias no se desempeñan mejor que las democracias de consenso en términos de gobierno efectivo y efectivo diseño de políticas públicas-de hecho, las democracias de consenso tienen un mejor récord-pero las democracias de consenso sí se desempeñan mejor que las mayoritarias en lo que respecta la calidad de la democracia, la representación democrática y sobre lo que me he referido como amabilidad y cuidado de la orientación de sus políticas públicas. (Lijphart 2012, p. 295)

Ahora bien, asumiendo que las democracias más justas, es decir, aquellas que son más democráticas, tenderán a tener mejores resultados en lo que Lijphart denomina calidad de representación democrática y calidad de la democracia, es posible anticipar que una democracia que verdaderamente cumpla con sus cometidos tenderá a tener ciertas formas identificables. Es decir, en contra de la comprensión de la democracia como procedimiento de Schumpeter, de las instituciones democráticas no se debería de seguir, en la medida en que verdaderamente sean democráticas y cumplan con los valores democráticos mismos, cualquier tipo de arreglo institucional o actos políticos concretos. Si la apreciación anterior es correcta, podemos derivar que las democracias más justas tienden a ser más proporcionales que mayoritarias.

En el siguiente apartado intentaré esbozar las diferencias que surgen de acuerdo a los arreglos institucionales, en el marco de la justicia distributiva, de cada tipo de democracia. Para esto aceptaré que las democracias pueden ser razonablemente clasificadas como mayoritarias y proporcionales y que, del mismo modo, esa clasificación es reflejo del modo en que se incorporan los valores democráticos de la igualdad y la libertad como elementos fundamentales de la democracia como sistema de justicia procedimental.

\section{Democracia, justicia procedimental y justicia distributiva}

Si la justicia procedimental, ordenada por ciertos principios políticos democráticos fundamentales, organiza las instituciones políticas básicas de una sociedad democrática, ¿tiene implicaciones en los mecanismos de organización y distribución de bienes?

Torsten Persson y Guido Tabellini han llevado a cabo un exhaustivo estudio sobre los efectos económicos de las diversas constituciones dentro de las sociedades democráticas (Persson \& Tabellini 2003). Recordando la postura schumpeteriana, las distinciones estructurales entre las constituciones políticas de diversas sociedades democráticas, asumiendo que algunas son más democráticas que otras, no deberían acarrear tendencias diferenciadas de modo claro sobre las políticas públicas en materia económica y social. Al final del día, si Schumpeter está en lo correcto, el mecanismo de elección democrático simplemente sirve para imponer en el poder a un oficial que, a su vez, hará con el poder político aquello que a él le parezca, en cierto sentido, mejor.

La hipótesis de investigación de Persson y Tabellini, por su parte, es que hay una relación directa en el proceso de desarrollo de políticas públicas entre los siguientes factores: Reglas constitucionales que afectan decisiones políticas que, a su vez, afectan a los mercados y los resultados económicos y, consecuentemente, impactan 
a las preferencias políticas de los ciudadanos; las preferencias políticas terminan afectando, cíclicamente, las reglas constitucionales (Persson \& Tabellini 2003, p. 3).

Con lo anterior en mente enunciaré dos conclusiones pertinentes de Persson y Tabellini:

1. El tamaño del gobierno (uso del presupuesto para su mantenimiento en gasto corriente e inversión en diversos programas) varía en función a si la democracia es presidencialista (mayoritaria) o parlamentaria (de consenso o proporcional) de modo importante, entre un 5 y $8 \%$ del PIB en promedio (Persson \& Tabellini 2003, p. 162). Las democracias presidencialistas tienden a ser, dado el mecanismo de elección mayoritaria, menos representativa de las minorías. Es decir, una menor igualdad representativa para todos los ciudadanos impacta el tamaño del gobierno y, por tanto, su capacidad de ser un factor económico relevante.

2. Las democracias más antiguas y mejor establecidas tienden a tener gastos en políticas de bienestar mayores en la medida en que sean parlamentarias y proporcionales: "Mientras las democracias envejecen y permiten mayores oportunidades de participación política, el tamaño del Estado de bienestar incrementa. Este efecto de la democratización se observa sólo en las democracias proporcionales y parlamentarias y no entre las democracias presidenciales y mayoritarias.” (Persson \& Tabellini 2003, p. 173)

Ahora bien, estas conclusiones parecen apuntar a que la selección de los programas de gobierno y las políticas distributivas de las democracias, lo que incluiría el tamaño del aparato gubernamental y la capacidad de acción del Estado, tienden a ser sensibles a la idea de promover cierto modo de igualitarismo que garantiza que las condiciones de libertad e igualdad verdaderamente se sostengan. Es decir, parecería que una sociedad con un Estado que no reconozca su responsabilidad respecto de las condiciones de igualdad mínimas en la comunidad es uno que no responde a intereses democráticos en general.

El estudio de Persson y Tabelli se refiere a democracias dentro de dos muestras, una amplia y otra reducida. En general, cuando trata los efectos concretos en democracias viejas y bien establecidas, se refiere a un grupo reducido de 20 democracias: las mejores 20 según el ranking de Freedom House. En las democracias bien establecidas las libertades están más o menos garantizadas, así como su posesión de un Estado de derecho y la garantía de derechos de propiedad. Es decir, estas naciones no podrían ser objeto de la crítica de la tiranía de la mayoría, que en cualquier momento despoja a los pocos ricos de sus bienes.

Si analizamos las decisiones en política económica de las democracias, como lo hace el estudio de Persson y Tabellini, queda la cuestión de si esas distinciones pueden ser juzgadas en relación a la justicia. Con lo dicho hasta ahora me parece que pueden ser estipuladas diversas opciones:

1. Las distinciones entre los efectos de las constituciones pueden ser analizadas en términos de justicia, como hubiera podido considerar Schumpeter, ya que no hay una idea de bien propia de la democracia que nos permita hacer ese juicio.

2. Podríamos suponer que las democracias de las que estamos hablando se 
refieren a una idea del bien no descrita dentro de los términos mismo de la democracia.

3. Las diversas democracias pueden ser juzgadas en la medida en que cumplan con los valores democráticos fundamentales y, por eso, sus políticas públicas se pueden juzgar como justas o injustas en función a los valores democráticos mismos.

En lo que respecta a la concepción de Schumpeter hay un problema fundamental: cuando hablamos de democracia, para verdaderamente poder describir un proceso como democrático, implicamos ciertos juicos de valor, entre los que se encuentran los valores de la igualdad, la libertad y, en algunos casos, la tolerancia por ejemplo. Si dichos valores son integrales a una comprensión de la democracia como un sistema de justicia procedimental, podríamos juzgar los actos políticos como justos o injustos en función a ellos mismo. Estos juicios de valor, que están incluidos en la definición de democracia, nos permiten realizar una evaluación del proceso de toma de decisión y cesión del poder democráticos que no se limitan a la concepción shumpeteriana.

La segunda opción, en función a una idea del bien determinada, nos presenta un problema complejo cuando recordamos que las democracias contemporáneas son plurales. En la medida en que el pluralismo nos impida llegar a una idea del bien común compartida, afirmaremos que cualquier análisis sobre la justicia de una política económica concreta que descanse en una idea del bien particular será inaceptable para muchos de los ciudadanos. Si ese fuera el caso, la democracia es imposición.

Dadas las objeciones anteriores, me parece que la última, de la justicia procedimental, es la mejor opción. Descansa en la idea que la democracia, para ser tal, depende de ciertos valores y que las instituciones encarnan esos valores de mejor o peor modo. Las democracias que encarnen mejor los principios de representación, que de algún modo supone la igualdad y la libertad, tenderán a poseer ciertas instituciones políticas, parlamentarias y proporcionales en la mayoría de los casos, $\mathrm{y}$, al parecer, tenderán a llevar a cabo ciertas políticas económicas concretas que tiendan al Estado de bienestar. Este juicio no se refiere a si dichas políticas son eficientes, sino a si son justas en función a la democracia misma.

Para terminar, un ejemplo adicional podrá servir. Estados Unidos ha logrado considerarse, en el ideario popular, como la democracia por antonomasia; sin embargo el registro histórico pone esta idea, por decirlo de algún modo, en duda. En la formulación inicial de la constitución americana es bien sabido que existían dos preocupaciones presentes respecto de la democracia, aunque no eran las únicas dos por supuesto: el temor a la tiranía de la mayoría (en términos de Madison la preocupación por la formación de facciones, en especial por las de carácter mayoritario (Madison 2003)) y la necesidad de mantener la unión entre las 13 colonias como condición de defensa y estabilidad a futuro, como ocupó especialmente a Hamilton (Hamilton 2003); estos son temas recurrentes, por ejemplo, en El Federalista. Los fundadores de la república norteamericana tenían conciencia de que ganar la independencia y poder mantenerla requería que las colonias se mantuvieran unidas como una nación.

Estas dos preocupaciones condujeron a que la constitución americana, como lo diagnostica Robert Dahl en su clásico texto, How Democratic is the American Constitution, estuviera llena de concesiones antidemocráticas. La más relevante es 
la desigualdad de representación garantizada por dos instituciones: el senado y el colegio electoral. Por un lado, el colegio electoral genera el problema de que el debate y la agenda pública tienden a estar controlados por los denominados "swing states"; es decir aquellos que podrían votar por cualquiera de los candidatos. En la medida en que Nueva York, por ejemplo, es demócrata, los candidatos a la presidencia tienden a ser negligentes con los intereses de los neoyorquinos, ya sea porque tienen su voto ganado o perdido incluso antes de iniciar elección, siempre y cuando las tendencias sean estables en el tiempo. Por supuesto puede suceder que con el paso del tiempo los Estados que normalmente ya tienen una preferencia se hagan "swing states", aunque la experiencia histórica no apunta a que eso suceda en una elección aislada. De cualquier modo, probablemente el efecto más antidemocrático del colegio electoral es que un candidato a la presidencia puede ganar una elección al obtener la mayoría del colegio aun perdiendo el voto popular.

En lo que se refiere al senado norteamericano, garantiza que cada Estado de la Unión tenga dos representantes independientemente del tamaño de su población. Es decir, Estados densamente poblados tendrán el mismo número de senadores que los que tengan las poblaciones más pequeñas; de esta manera el voto y los intereses de aquellos en esos Estados menores tienen mayor influencia que el de los mayores. La razón por la que se concibió el senado del modo en que se hizo fue, distinto al temor de la tiranía de la mayoría, como es el caso de los colegios electorales, para mantener contentos a los Estados esclavistas que temían, al aceptar formar parte de una nación con una constitución para todos, que los Estados del norte, de tendencia antiesclavista, prohibieran la esclavitud (Dahl 2003, pp. 12-15). La estructura del senado, así como la dificultad para realizar enmiendas constitucionales, garantizó que se llevara a cabo la unión.

Esa formulación del senado, con la falta de representación, permitió la existencia de la esclavitud hasta la segunda mitad del siglo XIX. Ahora bien, es difícil encontrar hoy en día personas que defiendan la esclavitud; sin embargo, ¿qué razones podemos dar para explicar su injusticia? El amplio consenso sobre la injusticia de la esclavitud, que no era tan amplio hace un poco más de 100 años, podríamos analizarlo con las siguientes opciones:

1. Siguiendo el análisis de Schumpeter, la esclavitud no puede ser juzgada de justa o injusta por sí misma en el contexto de las democracias. Es decir, podríamos decir que la esclavitud es injusta para nosotros pero no lo era para los Estados del sur en tiempos de la esclavitud y, por tanto, cuando los Estados del norte buscaron deshacer esa institución económica por vías democráticas, de modo fallido, lo que intentaron fue un acto de "imperialismo cultural".

2. La opción de la justicia procedimental nos da las mejores opciones para afirmar la injusticia de la esclavitud en el contexto de las sociedades democráticas. Por un lado, aun si la esclavitud hubiera Estado permitida en la primera versión de la constitución americana, si hubiera existido una representación igualitaria, donde las instituciones de toma de decisión hubieran sido hechas considerando la igualdad implícita en la idea de democracia, la esclavitud hubiera dejado de existir rápidamente y sin la necesidad de recurrir a una guerra civil. Lo considero así por al menos dos razones: (i) una parte importante de la población blanca estaba en contra de la esclavitud, desde el inicio, como una institución económica reconocida, por eso fue necesario el Senado como 
fue constituido. (ii) Si la igualdad de las personas de color y las personas blancas hubiera sido reconocida en el proceso democrático, la esclavitud es impensable; recordemos que en el caso de los esclavistas norteamericanos nunca existieron dudas de que las personas de color fueran efectivamente personas. Esto es evidente en la medida en que la población esclava era contabilizada en los censos para el cálculo de los colegios electorales y, del mismo modo, se reconoció el título de hombres libres a personas de color desde la fundación de Estados Unidos.

De este segundo modo parece que podemos hacer un juicio razonable de por qué la esclavitud fue injusta desde criterios democráticos entendiendo la democracia como un sistema de justicia procedimental.

\section{Conclusiones}

La consideración de la democracia como un sistema de justicia procedimental permite articular un concepto de este modo de gobierno que pueda hacer compatible el hecho del pluralismo y la necesidad de poder establecer un sistema que pueda ser considerado como justo por los ciudadanos. La necesidad de dicho sistema estriba, en mi opinión, en que si aquellos que viven en sociedad no sienten que están en una condición justa, las instituciones que conforman nuestras sociedades serán inestables siempre.

Aun cuando sea posible pensar en la sociedad como un sistema de cooperación injusto, pues aquellos que son víctimas de injusticia pueden creer que la cooperación pueda ser beneficiosa y, por lo mismo, valga la pena estar en una condición injusta, es claro que en el momento en que aquellos que se consideren víctimas puedan cambiar las condiciones injustas lo harán. Si el sistema democrático puede establecer los parámetros para que ciertos actos políticos puedan ser considerados un mal pero, al mismo tiempo, justos, las instituciones podrán ser estables en el tiempo. Lo que sería un requisito deseable de cualquier sistema de gobierno.

Aunque considero que la comprensión de la democracia como un sistema de justicia procedimental es superior a la propuesta schumpeteriana y evita, al mismo tiempo, una idealización de la democracia como cultura al modo de Dewey (Dewey 2013) o, igualmente, pensadores como Barber (Barber 2003), y los problemas que dicha idealización genera, de cualquier manera deja abiertas líneas de investigación que requieren ser analizadas. A continuación me gustaría señalar tan solo dos problemas que quedan pendientes de un trato a profundidad:

Primero, en la medida en que la justicia del proceso no está determinada por valores o factores sustantivos, ${ }^{4}$ ¿qué papel queda dentro del espacio público para ideas como la de la verdad? El concepto de la verdad es problemático en sí mismo, sin embargo, incluso en aquellos modos de comprenderla en que es más fácil llegar a un consenso, como es con las verdades científicas elaboradas desde una epistemología falsacionista, no es evidente cuál es su papel en el espacio público democrático. Esta es una cuestión que exige un trato serio pues, sin duda, negar que ciertos tipos de verdades deben de servir como un criterio normativo puede acarrear conclusiones

4 "Comprehensivos" en términos de Rawls. 
serias. La cuestión de asumir que la justicia y la verdad no están relacionadas pone en duda algunos de, lo que Rawls llamaría, nuestros juicios considerados.

Segundo, si el concepto de la justicia, en el marco de una sociedad plural,únicamente puede ser razonablemente defendido mediante la idea de la justicia procedimental, ¿es posible tener relaciones de justicia con individuos que no compartan nuestra idea de que el procedimiento es justo?, ¿es posible tener relaciones justas entre naciones cuando, al menos una de las partes, no aceptan nuestra comprensión de la democracia como sistema de justicia procedimental? Estas cuestiones ponen la cuestión del contextualismo político al frente de la discusión.

\section{Referencias bibliográficas}

Barber, Bejamin (2003): Strong democracy, participatory politics for a new age, Berkeley, Berkeley University of California Press.

Cohen, Joshua (2009): "Procedure and Substance in Deliberative Democracy"; en Philosophy, Politics, Democracy, Cambridge, Harvard University Press.

Dahl, Robert (1998): On Democracy, New Haver, Yale University Press.

Dahl, Robert (2012): How Democratic is the Constitution?, New Haven, Yale University Press.

Dewey, John (2013): Democracy and Education, Dehli, Aakar.

Geuss, Raymond (2001): History and Illusion in Politics, Cambridge, Cambridge University Press.

Hamilton, Alexander (2003). "Federalist no. 9", en Charles Kesler (ed.), The Federalist Papers, Nueva York, Signet Classics.

Lijphart, Arend (2012): Patterns of Democracy, New Haven, Yale University.

Madison, James (2003): “Federalist no. 10", en Charles Kesler (ed.), The Federalist Papers, Nueva York, Signet Classics.

Przeworski, Adam (2010): Democracy and the Limits of Self-Government, Cambridge, Cambridge University Press.

Rawls, John (1999): A Theory of Justice, Cambridge, Harvard University Press.

Rawls, John (2005): Political Liberalism, Nueva York, Columbia University Press.

Schumpeter, Joseph (2008): Capitalism, Socialism and Democracy, Nueva York, Harper Perennial.

Torsten \& Guido Tabellini, Guido (2005): The Economic Effects of Constitutions, Cambridge, The MIT Press. 